\title{
MUSCULOSKELETAL INJURIES IN MOTORCYCLE ACCIDENTS
}

\author{
Pedro Debieux, Carla Chertman, Nacime Salomão Barbachan Mansur, Eiffel Dobashi, Helio Jorge Alvachian Fernandes
}

\section{ABSTRACT}

Study conducted in the city of São Paulo from January 2001 to July 2002 with the goal of analyzing the profiles of individuals involved in motorcycle accidents, evaluating the rider's profile, the circumstances of the accidents, injuries, and the use of protective gear. 387 patients needing only traumatic orthopedic treatment were found, between 16 and 44 years of age, of which 354 were males (91.0\%). The most common mechanism of trauma involved a collision between the motorcycle and another vehicle (67.0\%) at a speed between 12.5-37.5 mph (73.0\%) involving less experienced riders (67.0\%) between 21 and 24 years of age (45\%), and in which 532 (53.9\%) lower limb inju- ries occurred. Of the injuries, 393 (39.8\%) were wounds, 314 (31.8\%) were bruises and $212(21.5 \%)$ were fractures [foot, 34 (16\%); femur, 32 (15.1\%); ankle, 27 (12.7\%); tibia, 25 (11.8\%)]. Recurring accidents were observed in 231 (60.0\%) cases and only $6.0 \%$ of the riders were not using protective equipment. Increased speed showed a higher rate of fractures when the Mann-Whitney test was applied ( $p=0.001)$. Research on mechanical and traffic engineering, in combination with supervision and awareness-raising of the population, should be considered the most effective methods of prevention

Keywords: Motorcycles. Accidents, traffic. Trauma.

Citation: Debieux P, Chertman C, Mansur NS, Dobashi E, Fernandes HJ. Musculoskeletal injuries in motorcycle accidents. Acta Ortop Bras. [online]. 2010;18(6):353-6. Available from URL: http://www.scielo.br/aob.

\section{INTRODUCTION}

Among the external causes we emphasize traffic accidents that are associated with a high mortality rate in the age bracket between one and fifty years (specific mortality of $19.8 \%$ ).

Studies on the patterns of injuries of traffic accident victims aim to describe the types, the locations and the different kinds of trauma.

An analysis by the Ministry of Health revealed that motorcycle accidents were those with the highest growth rates in the country since the 1990s. While in 1990 there were 299 deaths with accidents involving motorcycles, in 2006 this figure climbed to 6,734 , which represents growth of $2.252 \%$. ${ }^{1}$

Accidents determine a series of individual losses and losses for society such as: high medical and hospital expenditures; occurrence of temporary or permanent sequelae; disability; death; loss of days of work; expenditure with compensation; etc. The trauma resulting from these accidents represents one of the most challenging entities on account of its destructive power and growing incidence on modern life.
The aim of this study is to evaluate in patients that were admitted for treatment in the Orthopedics and Traumatology Emergency Room: the type of accident, the type of injury, the anatomical location, the length of experience of the accident victims and to correlate the injuries found with the speed at the time of trauma and with the use of safety equipment.

\section{MATERIAL AND METHODS}

Medical records were assessed between January 2001 and July 2002 for the gathering of information by the researchers involved from the Department of Orthopedics and Traumatology of Universidade Federal de São Paulo (UNIFESP), with Hospital São Paulo acting as the survey headquarters.

Our case study involved motorcycle accident victims that required orthopedic treatment. Patients with comorbidities that required multidisciplinary treatment in hospitalization were excluded.

Hence the patients that formed this survey came from two origins:

All the authors declare that there is no potential conflict of interest referring to this article.

Department of Orthopedics and Traumatology of Universidade Federal de São Paulo - UNIFESP - Escola Paulista de Medicina

Study developed in the Department of Orthopedics and Traumatology of UNIFESP - Escola Paulista de Medicina

Mailing Address: Rua Al Joaquim Eugenio de Lima, 1041. São Paulo-SP CEP 01403000

Departamento de Ortopedia e Traumatologia da UNIFESP - Escola Paulista de Medicina. Jd. Paulista São Paulo-SP. Brazil. Email: pedrodebieux@yahoo.com.br

Article received on 8/7/09 and approved on 10/6/09 
a) Those that sought medical care directly from the Orthopedics and Traumatology Emergency Room spontaneously.

b) Those referred by a multidisciplinary team headed by a General Surgeon from the Hospital after the verification of musculoskeletal injuries of exclusively orthopedic treatment.

Of a total 282,672 consultations held in the Emergency Room during this period, 62,505 patients were registered that were evaluated in Orthopedics. Of these 387 were motorcycle accident victims, 354 (91.0\%) of whom were male and $33(9.0 \%)$ female. The following parameters were analyzed:

a) The type of accident considering simple fall and collision (motorcycle with motorcycle, motorcycle with other automotive vehicle, motorcycle against structure).

b) Distribution of injuries according to the body segment: head, spine, upper limbs and lower limbs.

c) Distribution of traumas in conformity with the type of injury, considering: wounds (superficial or deep), bruises, fractures (closed or exposed), dislocations, sprains, ligament injuries, tendon injuries, nerve injuries and vascular injuries.

d) Distribution of accident victims according to their age, considering age brackets divided up into four year groups starting at 16 and ending at 44 years of age.

e) Speed of the motorcycle at the time of the accident: up to $20 \mathrm{~km} / \mathrm{h}, 20-40 \mathrm{~km} / \mathrm{h}, 40-60 \mathrm{~km} / \mathrm{h}, 60-80 \mathrm{~km} / \mathrm{h},>80 \mathrm{~km} / \mathrm{h}$.

f) Distribution of injuries considering the speed of the motorcycle at the time of the accident: up to $20 \mathrm{~km} / \mathrm{h}, 20-40 \mathrm{~km} / \mathrm{h}, 40$ $60 \mathrm{~km} / \mathrm{h}, 60-80 \mathrm{~km} / \mathrm{h},>80 \mathrm{~km} / \mathrm{h}$.

g) Reoccurrence or non-reoccurrence of the motorcycle accident.

h) Length of experience of the riders involved in accidents: up to 5 years, 5-10 years, $10-15$ years, $>15$ years.

i) Use of passive protection equipment: no type; helmet; helmet and gloves; helmet and boots; helmet and special clothing; helmet, gloves and boots; helmet, gloves and special clothing; helmet, gloves, boots and special clothing.

j) Relationship between the rates of the most frequent traumatic injuries and the speed at which the traumas occurred.

\section{RESULTS}

As regards the type of accident, we observed a predomination of 258 e (67.0\%) collisions between motorcycle and car followed by simple fall, which represents 78 (20.0\%) accidents. (Table 1)

Table 1 - Frequency of the types of accident

\begin{tabular}{c|c|c}
\hline Type of accident & Frequency $(\mathbf{n})$ & Percentage(\%) \\
\hline Motorcycle/vehicle & 258 & 67 \\
\hline Fall & 78 & 20 \\
\hline Motorcycle/Structure & 28 & 7 \\
\hline Motorcycle/Motorcycle & 23 & 6 \\
\hline Total & 387 & 100 \\
\hline
\end{tabular}

Source: SAME HSP

According to the distribution of injuries considering the body segment, we obtained 532 (53.9\%) on the lower limbs, 396 (41.1\%) on the upper limbs, 31 (3.1\%) in the cephalic segment and 28 (2.8\%) on the spine, (Table 2) with 193 (19.1\%) located on the knee, 96 (9.7\%) on the ankle, 94 (9.6\%) on the hand, $84(8.5 \%)$ on the leg, $83(8.4 \%)$ on the shoulder, 81 (8.2\%) on the elbow and $73(7.4 \%)$ on the foot. (Table 3$)$
Table 2 - Injuries by body segments

\begin{tabular}{c|c|c}
\hline Location & Frequency(n) & Percentage(\%) \\
\hline ULs & 532 & 53.9 \\
\hline LLs & 396 & 41.1 \\
\hline Cephalic segment & 31 & 3.2 \\
\hline Spine & 28 & 2.8 \\
\hline Total & 987 & 100 \\
\hline
\end{tabular}

Source: SAME HSP

Table 3 - Specific distribution of injuries

\begin{tabular}{c|c|c}
\hline Location & Frequency $(\mathbf{n})$ & Percentage(\%) \\
\hline Knee & 193 & 19.6 \\
\hline Ankle & 96 & 9.7 \\
\hline Hand & 94 & 9.6 \\
\hline Leg & 84 & 8.5 \\
\hline Shoulder & 83 & 8.4 \\
\hline Elbow & 81 & 8.2 \\
\hline Foot & 73 & 7.4 \\
\hline Wrist & 62 & 6.3 \\
\hline Thigh & 50 & 5.0 \\
\hline Forearm & 44 & 4.7 \\
\hline Total & 860 & 100 \\
\hline
\end{tabular}

Source: SAME HSP

As regards the types of injury, we obtained 393 (39.8\%) wounds, $314(31.8 \%)$ bruises, $156(15.8 \%)$ closed fractures, 56 (5.7\%) exposed fractures, $30(3.0 \%)$ dislocations, $17(1.7 \%)$ vascular injuries, $17(1.7 \%)$ sprains, 9 (0.9\%) ligament injuries, 7 (0.7\%) tendon injuries and 5 (0.5\%) nerve injuries. (Table 4)

\begin{tabular}{c|c|c}
\multicolumn{3}{|c}{ Table 4 - Types of injury encountered } \\
\hline Injury & Frequency (n) & Percentage(\%) \\
\hline Wound & 393 & 39.8 \\
\hline Bruise & 314 & 31.8 \\
\hline Fracture & 156 & 15.8 \\
\hline Exposed fracture & 56 & 5.7 \\
\hline Dislocation & 30 & 3.0 \\
\hline Sprain & 17 & 1.7 \\
\hline Vascular injury & 17 & 1.7 \\
\hline Ligament injury & 9 & 0.9 \\
\hline Tendon injury & 7 & 0.7 \\
\hline Nerve injury & 5 & 0.5 \\
\hline Total & 1004 & 100
\end{tabular}

Source: SAME HSP

Bearing in mind the location of the fractures we found 34 (16\%) on the bones of the foot, 32 (15.1\%) on the femur, $27(12.7 \%)$ on the ankle, $25(11.8 \%)$ on the bones of the hand, $20(9.4 \%)$ on the wrist, $16(7.5 \%)$ on the clavicle and 34 (16\%) distributed around the remaining bones. (Table 5)

Considering the distribution of accident victims according to age, we observed 75 (19.0\%) individuals between $16-20$ years of age, 172 (45.0\%) between 21-24, 59 (15.0\%) between 25-28, 33 (9.0\%) 
Table 5 - Distribution of fractures encountered.

\begin{tabular}{c|c|c}
\hline Location & Frequency $(\mathbf{n})$ & Percentage(\%) \\
\hline Foot & 34 & 16.0 \\
\hline Femur & 32 & 15.1 \\
\hline Ankle & 27 & 12.7 \\
\hline Tibia/Fibula & 25 & 11.8 \\
\hline Hand & 23 & 10.8 \\
\hline Wrist & 20 & 9.4 \\
\hline Clavicle & 16 & 7.5 \\
\hline Others & 34 & 16.0 \\
\hline Total & 211 & 100 \\
\hline
\end{tabular}

Source: SAME HSP

between 29-32, 27 (7.0\%) between 33-36, 16 (4.0\%) between $37-40$ and 5 (1.0\%) between 41-44 years of age.

As regards speed of the motorcycle at the time of the accident, $39(10.0 \%)$ occurred up to $20 \mathrm{~km} / \mathrm{h}, 105$ (27.0\%) between $20-40$ km/h, 117 (46.0\%) between 40-60km/h, 57 (15.0\%) between 60$80 \mathrm{~km} / \mathrm{h}$ and $9(2.0 \%)$ over $80 \mathrm{~km} / \mathrm{h}$. (Table 6)

\begin{tabular}{c|c|c}
\multicolumn{3}{|c}{ Table 6 - Distribution of patients according to speed } \\
\hline Speed (Km/h) & Patients(n) & Percentage(\%) \\
\hline $0-20$ & 39 & 10 \\
\hline $20-40$ & 105 & 27 \\
\hline $40-60$ & 177 & 46 \\
\hline $60-80$ & 57 & 15 \\
\hline$>80$ & 9 & 2 \\
\hline Total & 387 & 100 \\
\hline
\end{tabular}

Source: SAME HSP

The distribution of injuries considering speed of the motorcycle at the time of the accident (up to $20 \mathrm{~km} / \mathrm{h}, 20-40 \mathrm{~km} / \mathrm{h}, 40-60 \mathrm{~km} / \mathrm{h}$, $60-80 \mathrm{~km} / \mathrm{h},>80 \mathrm{~km} / \mathrm{h}$ ) is discriminated in Figures 1, 2, 3, 4 and 5 respectively.

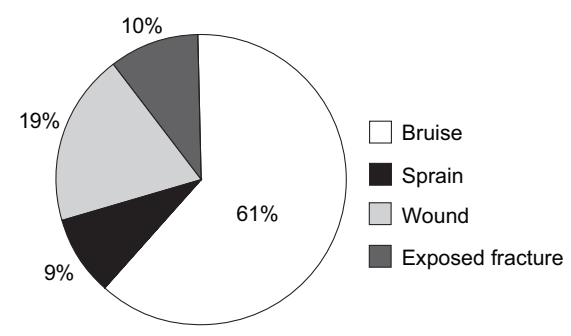

Figure 1 - Distribution of injuries with speed up to $20 \mathrm{Km} / \mathrm{h}$.

We observed that 231 (60.0\%) patients had suffered accidents previously and 156 (40.0\%) suffered the accident for the first time. Among riders, 258 (67.0\%) had experience riding motorcycles for up to five years, 84 (22.0\%) between $5-10$ years, 25 (6.0\%) between $10-15$ years and 20 (5.0\%) more than 15 years.

As regards the use of protection equipment, we observed that $262(67.0 \%)$ used a helmet; 47 (12.0\%) did not use any equipment; 25 (6.0\%) used helmet and gloves; 20 (5.0\%) helmet and boots; 18 (5.0\%) helmet and special clothing; 10 (3.0\%) helmet, gloves and boots; 3 (1.0\%)helmet, gloves and special clothing;

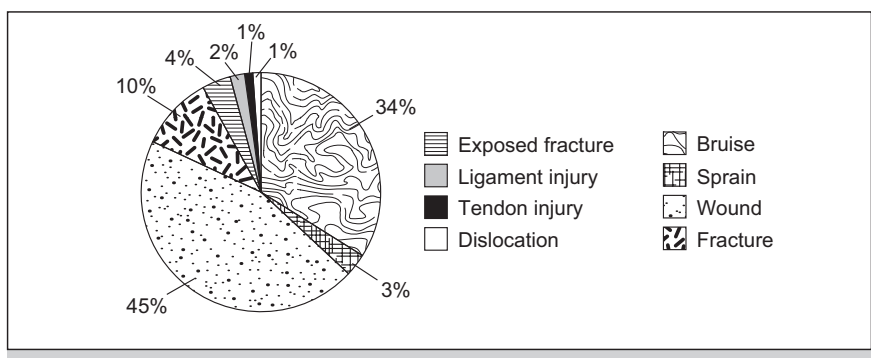

Figure 2 - Distribution of injuries with speed between 21 and $40 \mathrm{Km} / \mathrm{h}$.

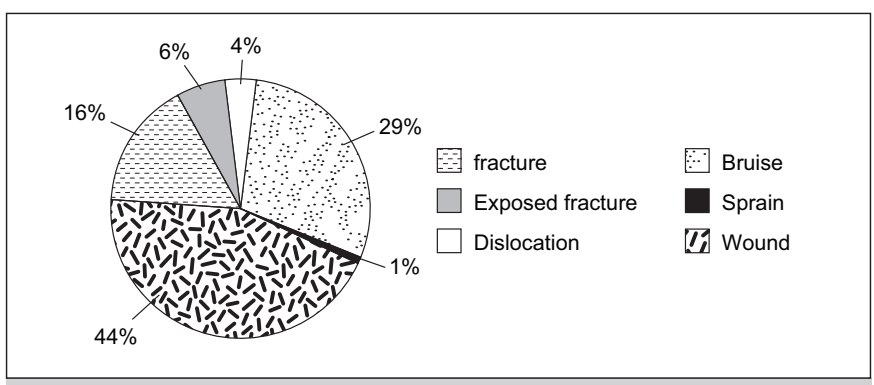

Figure 3 - Distribution of injuries with speed between 41 and $60 \mathrm{Km} / \mathrm{h}$.

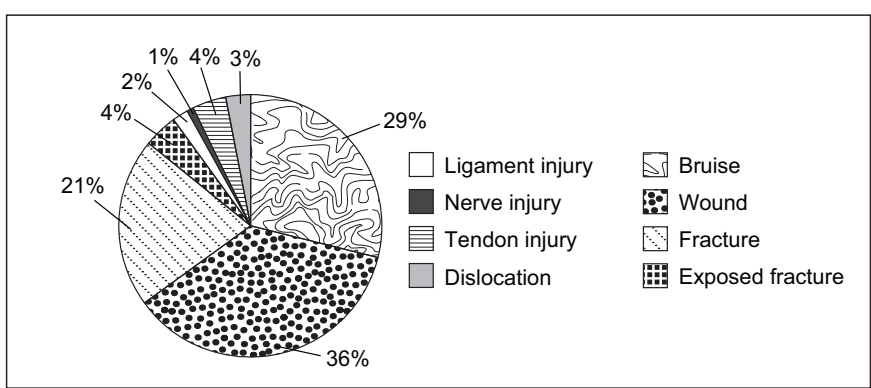

Figure 4 - Distribution of injuries with speed between 61 and $80 \mathrm{Km} / \mathrm{h}$.

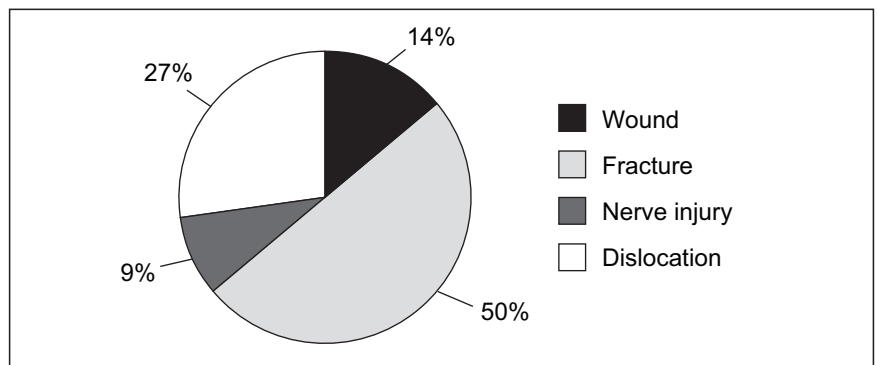

Figure 5 - Distribution of injuries with speed above $80 \mathrm{Km} / \mathrm{h}$.

$2(1.0 \%)$ helmet, gloves, boots and special clothing.

In relation to the type of injury (bruise, wounds and fractures) considering the speed at which the accidents occurred, we observed: a decrease in the rate of bruises with the progression of speed; significant increase of the rate of fractures with the increase of speed when applying the Mann-Whitney test $(p=.001)$. (Table 7)

\section{DISCUSSION}

According to information from the National Traffic Department (DENATRAN), there were around 2 million licensed motorcycles in the State of São Paulo in April 2008 and more than 9 million formed the 
Table 7 - Distribution of injuries according to speed increase

\begin{tabular}{c|c|c|c}
\hline Speed $(\mathrm{Km} / \mathrm{h})$ & Bruise & Wound & Fracture \\
\hline $0-20$ & $41(69.5 \%)$ & $10(16.9 \%)$ & $8(13.6 \%)$ \\
\hline $21-40$ & $76(35.0 \%)$ & $100(46.1 \%)$ & $41(18.9 \%)$ \\
\hline $41-60$ & $146(30.9 \%)$ & $216(45.7 \%)$ & $111(23.5 \%)$ \\
\hline $61-80$ & $47(32.2 \%)$ & $55(37.7 \%)$ & $44(30.1 \%)$ \\
\hline$>80$ & $4(16.7 \%)$ & $12(50 \%)$ & $8(33.3 \%)$ \\
\hline
\end{tabular}

Source: SAME HSP

national fleet in the same period. And the number of accident victims has grown considerably when compared with the other types, attaining as much as $90 \%{ }^{2}$

For motorcycle riders, the exposure and consequent absorption of kinetic energy from their whole body surface to the trauma makes them extremely vulnerable.

The cause of accidents is multifactorial and is related to a combination of factors with special emphasis on: motorcycle conservation conditions; state of preservation of public roads; signposting; speed of the vehicles involved; visibility; traffic conditions; influence of rain; respect for the legislation and inspectors; human factor.

As regards the conditions of the motorcycles, according to data from Companhia de Engenharia de Trafego, motorcycles produced up to 1985 were involved in $43 \%$ of the fatal accidents, those produced between 1986 and 1990 in 32\% and those produced between 1991 and 1996 in 25\%.

In spite of all the issues mentioned, human error is probably still responsible for the majority of accidents. Another important matter, yet without statistical support, is related to alcohol consumption. ${ }^{3-4}$ We believe that traffic re-education programs have a direct impact on statistic and should be emphasized.

Reinforcing this hypothesis, we verified in our material that the distribution of accident victims reveals a greater concentration of very young individuals affected, under 28 years of age (79.0\%), peaking between the ages of 21 and 24 years (45.0\%). Within this population we also noticed that the highest number of accidents occurred with people with less than 5 years of experience in riding motorcycles (67.0\%), with reoccurrence of $60.0 \%$.

As regards the distribution of these injuries over the body, they occur mainly at the level of the lower limbs (29.8\%), of the cephalic segment (21.5\%) and of injuries of the body surface (18.1\%). ${ }^{2,5}$ Our results are concordant with those observed in medical literature, as $53.9 \%$ were evidenced on the lower limbs, $41.1 \%$ on the upper limbs, $3.1 \%$ in the cephalic segment and $2.8 \%$ on the spine. (Table 2) Using a different methodology from the distribution of injuries, Haddad et al. ${ }^{6}$ refer to $37.7 \%$ of dorsal impairment, $23.4 \%$ of the lower limbs, $20.8 \%$ of the head and neck and $16.9 \%$ of the upper limbs. The most common pattern is the presentation of patients with multiple injuries, of which $72.0 \%$ have other associated injuries. ${ }^{2}$ We did not conduct this analysis in our survey.

The inadequacy of some protection equipment and the drivers' cavalier attitude towards their use are associated with a high rate of injuries. The use of helmets appears to be the only item of equipment of motorcycle riders recognized worldwide as an effective method of minimizing the effects of trauma to the cephalic segment. ${ }^{7-9}$ The relationship between helmet use and the occurrence of head injury is a frequent subject of investigation. The non-use of this safety device is verified between $72 \%$ and $75 \%$ of hospitalized patients. ${ }^{2}$ We came across $12.0 \%$ that did not use any kind of safety equipment, including the helmet, yet we failed to find any correlation between the severity and the frequency of traumatic injuries, especially head injury.

Protective clothing, which would include reinforced footwear and leg protection, should somehow provide greater protection and, consequently, reduce the rate of injuries, particularly of the soft tissues. ${ }^{8,9}$ We executed an analysis considering the traumas and the speed of accidents. (Figures 1, 2, 3, 4 and 5) After application of the Mann-Whitney ${ }^{10}$ test we found a statistically significant correlation ( $p=0.001)$ where we verified that the greater the speed the higher number of fractures and the lower the number of bruises. (Table 7) This finding obviously corroborates the biomechanical assumptions that involve the trauma.

Lower limb injuries contribute with the highest rates of morbidity and prolonged hospital stay 2,4 and contribute from $18 \%$ to $80 \%$ of all the injuries. ${ }^{4}$ The greater severity of the fractures, bruises and wounds is listed in this study when the accident involves collision between the motorcycle and another vehicle $(67 \%)$, followed by isolated fall (20.0\%).

There is a high cost related to motorcycle accidents and we stress that attempts to reduce the physical, psychological and economic damage suffered directly by accident victims and their families, especially those that require a long period of treatment and leave from work, should be carefully studied and applied when possible.

\section{CONCLUSION}

Care with the health of motorcycle riders should involve professionals from the area of preventive health and the community, thus aiming to decrease the socioeconomic and medical impacts, since these individuals are usually young and at an age when they are fully productive.

We believe, going by the analysis of information obtained, that surveys in the field of mechanical engineering and of traffic engineering, associated with rigorous supervision and awareness enhancement campaigns for the population, should be considered. However, we emphasize that accident prevention, regardless of how this goal is attained, should always be prioritized.

\section{REFERENCES}

1. Koizumi MS. Padrão das lesões nas vítimas de acidentes de motocicleta. Rev Saúde Pública. 1992;26:306-15.

2. Richter M, Otte D, Jahanyar K, Blauth M. Upper extremity fractures in restrained front-seat occupants. J Trauma. 2000;48:907-12.

3. Rowland J, Rivara F, Salzberg P, Soderberg R, Maier R, Koepsell T. Motorcycle helmet use and injury outcome and hospitalization costs from crashes in Washington State. Am J Public Health. 1996;86:41-5.

4. Tomczak PD, Buikstra JE. Analysis of blunt trauma injuries: vertical deceleration versus horizontal deceleration injuries. J Forensic Sci. 1999;44:253-62.

5. Gonçalves RM, Petronianu A, Ferreira Junior JR. Características das pessoas envolvidas em acidentes com veículos de duas rodas. Rev Saúde Pública. 1999;31:436-7.
6. Haddad JP, Echave V, Brown RA, Scott HJ, Thompson G. Motorcycle accidents: A Review of 77 Patients Treated in a Three-Month Period. J TraumaInjury. 1976:16, 550-57.

7. Peek C, Braver ER, Shen H, Kraus JF. Lower extremity injuries from motorcycle crashes: a common cause of preventable injury. J Trauma. 1994;37:358-64.

8. Craig GR, Sleet R, Wood SK. Lower limb injuries in motorcycle accidents. Injury. 1983;15:163-6.

9. Haddon W Jr. Energy damage and the ten countermeasure strategies. J Trauma.1973;13:321-31.

10. Parreira GJ, Coimbra R, Rasslan S, Oliveira A, Fregoneze M, Mercadante M. The role of associated injuries on outcome of blunt trauma patients sustaining pelvic fractures. Injury. 2000;31:677-82. 